\title{
Cardiovascular Imaging Asia: Editor's Note
}

pISSN 2508-707X / elSSN 2508-7088 https://doi.org/10.22468/cvia.2020.00136 Cardiovasc Imaging Asia 2020;4(4):85-85

Received: December 23, 2020 Accepted: December 24, 2020

\section{Corresponding author} Sang \| Choi, MD, PhD Department of Radiology, Seoul National University Bundang Hospital, 82 Gumi-ro 173beon-gil, Bundang-gu, Seongnam 13620, Korea Tel: 82-31-787-7611 Fax: 82-31-787-4011 E-mail: drsic@hanmail.net

\author{
Sang II Choi \\ Department of Radiology, Seoul National University Bundang Hospital, Seongnam, Korea
}

The Asian Society of Cardiovascular Imaging (ASCI) provides academic activities online to share and update knowledge of academic leaders and provide basic knowledge about cardiovascular imaging. Currently, the CVIA is in the evaluation process of (e)SCl, and the result will be out early next year. In addition, the criteria of Scopus and Medline were pre-checked at the meeting with the publisher. Members are encouraged to quote as many papers published in CVIA as possible to help ensure that CVIA is highly publicized and exposed to search engines.

Key words Heart $\cdot$ Imaging $\cdot$ COVID-19.
Though the ongoing COVID-19 pandemic has spread, I hope that all readers and ASCI members are healthy and doing well. I apologize that the 2020 Oct. issue was not published at the appointed time. In this era of COVID-19, congressional meetings of the ASCI as well as many scheduled society activities such as joint symposiums are postponed or canceled. I think that the main reason for the reduced number of submitted articles is the ongoing COVID-19 pandemic and the reduced academic activities provided by the ASCI. Instead, the ASCI can provide academic activities online to share and update knowledge of academic leaders with ASCI members and provide basic knowledge about cardiovascular imaging to ASCI members.

However, thanks to continuous interest and contributions, the CVIA has been steadily growing as an international journal. I believe that development of academic journals is an essential process for academic societies to grow in quality. Currently, the CVIA is in the evaluation process of (e)SCI, and the result will be out early next year. In addition, the criteria of Scopus and Medline were pre-checked at the meeting with the publisher. Although it was not a short time to launch CVIA, I would like to thank the ASCI president, Professor Yung-Liang Wan, and all members for their support. In addition, I would like to ask to all the ASCI members to please cite as many CVIA

(a) This is an Open Access article distributed under the terms of the Creative Commons Attribution Non-Commercial License (https://creativecommons.org/licenses/bync/4.0) which permits unrestricted non-commercial use, distribution, and reproduction in any medium, provided the original work is properly cited. articles as possible for registration in SCI.

This year, a special article entitled, "Cardiac Imaging in the Era of the COVID-19: Review and Summary of the Guidelines of Cardiovascular Imaging Societies," provides information on measures for guidelines of safety and recommendations for cardiovascular imaging during the pandemic [1]. Another special article entitled, "Cardiovascular Manifestations of COVID-19," provides useful information for the cardiovascular manifestations of COVID-19 and their related imaging findings [2]. Once again, I would like to thank you for reading CVIA and hope you continue to read our special issues as well as current issues. Finally, I would like to express my heartfelt thanks to all reviewers and editorial boards who have dedicated time and helped us to publish the ASCI Journal.

\section{REFERENCES}

1. Kang JW, Kim W, Choi SI. Cardiac Imaging in the Era of the COVID-19: Review and Summary of the Guidelines of Cardiovascular Imaging Societies. Cardiovasc Imaging Asia 2020;4:67-73.

2. Kim JY. Cardiovascular Manifestations of COVID-19. Cardiovasc Imaging Asia 2020;4:74-80. 